\title{
POLÍTICAS DE CURRÍCULO PARA A EDUCAÇÃO DO CAMPO: DE QUE FORMA, SE FAZEM OS INVESTIMENTOS?
}

\author{
Jéssica Rochelly da Silva Ramos ${ }^{(*)}$ \\ Kátia Silva Cunha ${ }^{(* *)}$
}

\section{INTRODUÇÃO}

Na última década os discursos sobre padronização do ensino e homogeneização ganham destaque no campo das disputas nos currículos, esses discursos são articulados politicamente em torno de debates nas políticas curriculares que privilegiam as diferenças nos processos de formação, vislumbrando, com isso, a democracia nas políticas de currículo, a busca por uma qualidade na educação que seja fruto de dissensos, negociada e que ultrapasse os limites de um currículo centralizado e padronizado. Essa memória discursiva, principalmente na Educação do Campo, faz retomar com grande força as discussões em torno da homogenia e vem se apresentando como espaço de amplo debate e busca por inclusão, trazendo para o campo das políticas curriculares para a Educação do Campo, bem como para os possíveis currículos, estranhamentos, discussões, articulações discursivas, buscas por significação e pela fixação de conhecimentos que pretendem universalizar o ensino, como por exemplo, a Base Nacional Comum Curricular (BNCC).

Neste texto ${ }^{1}$, buscamos analisar os possíveis sentidos nas políticas curriculares para a Educação do Campo nos processos de constituição e elaboração das políticas, focalizando os contextos de influência, da produção de texto e da prática, investigando os consensos possíveis estabelecidos nas políticas que se tornaram hegemônicos (MOUFFE, 2005), considerando que estes processos são conflituosos, provisórios e contingentes, sujeitos sempre a flutuações de sentidos, frutos das articulações políticas engendradas nas negociações e no sistema de diferenças que operam na construção de uma política curricular.

\footnotetext{
(*) Jéssica Rochelly da Silva Ramos. Mestre em Educação Contemporânea e Pedagoga pela Universidade Federal de Pernambuco no Centro Acadêmico do Agreste.

${ }^{(* *)}$ Katia Silva Cunha. Doutora e Mestre em Educação pela Universidade Federal de Pernambuco. Professora Adjunta da Universidade Federal de Pernambuco no Centro Acadêmico do Agreste.

${ }^{1}$ Este texto foi construído a partir da dissertação de mestrado intitulada "Políticas Públicas e Educação do Campo: uma análise dos contextos discursivos que norteiam as escolas do campo no município do Brejo da Madre de Deus - PE", desenvolvida pela autora sob a orientação da Profa. Dra. Katia Silva Cunha e defendida em 2017, no Programa de Pósgraduação em Educação Contemporânea (PPGEDUC) do Centro Acadêmico do Agreste (CAA) da Universidade Federal de Pernambuco (UFPE), em Caruaru - PE. Para maior aprofundamento da temática, ver Ramos (2017).
} 
Com isto, não queremos nos atentar sobre uma origem, mas sobre a trajetória que ainda está em construção de uma Educação do e no Campo, e pelo fato de não ser fechada em uma política curricular fixa, a política de Educação do Campo, permite um repensar sobre o movimento de constituição dos sentidos, na (re)formulação de novas hegemonias, novas articulações, no sentido de "suprir" as demandas dos coletivos sociais existentes nesse espaço do social. Como essas políticas são recontextualizadas e/ou traduzidas pelos atores das políticas? Quais as normatividades que direcionam e impulsionam o deslocamento dos sentidos expressos em uma política de Educação Rural para uma política de Educação do e no Campo - com todo o aparato político e ideológico que este termo carrega? Quais os investimentos que estes docentes fazem nos processos de traduzir as políticas, ou melhor, no "entre-lugar" dos processos políticos?

Mediante esses questionamentos, buscamos analisar se diante da luta dos movimentos sociais do campo e da instituição legal de políticas públicas para a Educação do Campo, há um diálogo ou encaminhamento em consonância com os discursos produzidos no âmbito da prática pelos profissionais das escolas do campo, especificamente os docentes, estes que tem sua função presente no contexto da política enquanto prática, e muitas vezes nos demais contextos.

\section{ENCAMINHAMENTOS TEÓRICO-METODOLÓGICOS DA PESQUISA}

No campo das políticas curriculares no Brasil, a incorporação do enfoque teórico analítico desenvolvido por Ball, a exemplo de Lopes (2004; 2008), Lopes e Macedo (2011), largamente conhecido como Abordagem do Ciclo de Políticas (ACP) tem ganhado amplo debate nos escritos de Bowe et al. (1992), Ball e Mainardes (2011), além de viabilizar um conjunto de análises que tenta dar conta da complexidade das políticas curriculares. Assim sendo, a partir da ACP como abordagem para análise de políticas, especificamente as políticas Curriculares para a Educaão do Campo, é empreendido um esforço no sentido de romper com a verticalidade de leituras das políticas e dos currículos,

[...] seja por filiação estadocêntrica, circunscrição às determinações do mercado ou do capital, seja, no extremo oposto, pela crença na autonomia irrestrita de atores sociais localizados na prática das escolas (LOPES; CUNHA; COSTA, 2013, p. 393).

Nesse sentido, tratamos os processos da política a partir da ACP e ainda com as contribuições teóricas de Laclau e Mouffe (2015) para a compreensão da luta hegemônica na produção das políticas de Educação do Campo. Pensar nas políticas de Educação do Campo é pensar que estas políticas são constituídas por sujeitos descentrados, que falam de um lugar, produzem discursos a partir de contextos, saberes, fazeres. Estas abordagens nos permite entender a 
política de Educação do Campo na sua feitura, nas articulações que são engendradas no processo político e suas diferentes dimensões, bem como a negociação na/com a diferença, possibilitando a compreensão de que é na possibilidade do "entre-lugar" entre a política curricular e o vivido, que os campos de significação na "articulação-desarticulação-(re)articulação de enunciados [...] [se] evidenciam e deslocam a diferença" (FRANGELLA; BARREIROS, 2010, p. 13), e ao se recriar a partir dessas fronteiras fluidas, essa política, bem como o currículo dessas escolas do campo, tornase movediço, híbrido, na possibilidade do “entre-lugar” de enunciação.

Mendonça (2014), aproximando-se da concepção de discurso de Laclau e Mouffe, afirma que, "Discurso é uma categoria que une palavras e ações, que tem natureza material e não mental e/ou ideal. Discurso é prática - daí a ideia de prática discursiva” (MENDONÇA, 2014, p. 149). Portanto, compreendemos que não há uma separação entre política e prática, ao pensar a política a partir da categoria discurso, entendemos que há uma imbricação e permanente tensão entre o global e o local, sendo assim a ideia de prática discursiva, ou seja, um momento da política (LOPES; CUNHA; COSTA, 2013). Não há um sentido negativo nestas negociações ocorridas no "entre lugar” das políticas (BHABHA, 1998), ao contrário, estas mobilizações possibilitam que a tradução opere no propósito de ampliar o sentido de política.

\section{A CONSTITUIÇÃO DO CORPUS E DESENHO DA PESQUISA}

Visando compreender os contextos discursivos que norteiam as escolas do campo, fizemos a escolha de um município no Agreste pernambucano que se configura como elucidativo para nos auxiliar na compreensão do nosso objeto de estudo, a saber, Políticas de Educação do Campo. O número total de escolas que compõe a rede municipal do Brejo da Madre de Deus são 51 escolas, sendo 44 localizadas na área rural o que compreende cerca de 86,30\%, tendo apenas 7 escolas localizadas na área urbana o que compreende $13,70 \%$ do número total de escolas. No entanto, de modo a compreender os contextos discursivos que norteiam as políticas públicas para a Educação do Campo nas escolas do campo do município do Brejo da Madre de Deus - PE, decidimos por elencar 3 escolas que participaram do Programa Escola da Terra (2 $2^{\text {a }}$ edição) oferecido pela Universidade Federal de Pernambuco (UFPE/CAA) em 2015, este programa que é uma ação do Programa Nacional de Educação do Campo (PRONACAMPO).

Os sentidos expressos nas negociações e nos processos de tradução das políticas no contexto da prática foram acessados a partir do corpus de entrevistas realizadas com docentes de três escolas constituintes da rede de ensino municipal. A escolha por professores como participantes para a análise justificam-se a partir da ideia de que na escola e principalmente no espaço da sala de aula, as 
políticas de Educação do Campo são ressignificadas no âmbito da prática a partir da tradução que os sujeitos-atores, os docentes, fazem dessas políticas. Os atores traduzem as políticas a partir dos contextos culturais, concepções de territórios, saberes, histórias, entre outros elementos e momentos, e por isso, o processo de tradução torna-se um espaço complexo nas políticas, pois é neste processo que se articulam diversas culturas, é esse "entre lugar" que "carrega o fardo do significado da cultura" como nos diz Bhabha (1998, p. 69). E mais, o autor enfatiza que, "esses 'entre-lugares' fornecem o terreno para a elaboração de estratégias de subjetivação - singular ou coletiva - que dão início a novos signos de identidade e postos inovadores de colaboração e contestação" (BHABHA, 1998, p. 20).

\section{A PRODUÇÃo dE POLÍTICAS CURRICULARES PARA A EDUCAÇÃO DO CAMPO: DISPUTAS EM TORNO DE HEGEMONIA}

A trajetória de lutas e conquistas dos movimentos sociais na elaboração de políticas públicas para a Educação do Campo é marcada por processos de negociações e mobilizações políticas em torno do direito à educação, uma educação de qualidade vinculada a um projeto de Educação no e do Campo. Dessa forma, a Educação do Campo insurge de uma nova base conceitual sobre o campo e sobre a Educação do Campo, dito de outro modo trata-se de uma hegemonia - fruto das articulações dos atores políticos cuja demanda principal é uma Educação do e no Campo- que busca, sobretudo, a superação da hegemonia engendrada pelo Estado - de uma Educação Rural, como meio de exploração pelo trabalho dos povos do campo e do território campesino - esta que tem fortes influências dos poderes econômicos, um paradigma que, antes de tudo, projeta o campo como a faceta atrasada da sociedade.

A luta inicial por uma Educação do Campo é pela Reforma Agrária, essa demanda que ganha uma totalidade tornando-se hegemônica nas mobilizações e atuações políticas, mas que ao longo de sua trajetória vem alcançando maiores proporções e reconfigurando-se em torno de novas demandas, sendo o direito à educação e a uma educação diferenciada, os discursos que buscam construir um centro privilegiado que se fixe, embora parcialmente, constituindo um ponto nodal a partir das articulações discursivas e dos jogos entre diferenças e equivalências (LACLAU; MOUFFE, 2015). Estes novos discursos, deslocam o sentido inicial da luta e tornam o direito a uma educação diferenciada o principal objeto de luta e de mobilização política, a demanda que move a atuação política em torno de uma democracia mais radical e plural nas políticas curriculares para a Educação do Campo. 
Considerando, pois, que toda política curricular é uma política cultural, "o currículo é fruto de uma seleção de cultura e é um campo conflituoso de produção de cultura, de embates entre sujeitos, concepções de conhecimento, formas de entender e construir o mundo", como bem afirma Lopes (2004, p.111). As políticas de Educação do Campo, neste contexto, são marcadas por conflitos, negociações no campo das diferenças e equivalências em torno do direito à educação, tendo como principal demanda a diferença e, ao mesmo tempo, constitui-se enquanto principal objeto de luta desses sujeitos nas articulações políticas na defesa de um discurso de qualidade na educação, a saber, na Educação do Campo. O currículo neste contexto é questionado e entendido como um híbrido (LOPES, 2004; 2005; 2006), longe de ser um instrumento que tece uma 'síntese' das diferenças, de todo o conhecimento, de todos os valores, de todas as culturas. Levando essa reflexão mais longe, entendemos, pois, que o currículo é um terreno de negociações marcado pela contingência e precariedade.

Não se pode pensar, a partir da categoria discurso - lugar do qual falamos - pensar o currículo, bem como as políticas curriculares como documentos oficiais em seu fundamento último, pronto a ser executado. É deslocada a demanda de uma educação 'no' campo - apenas no território campesino - a luta ganha outro objeto político, a qualidade da educação do e no campo, princípio este vinculado principalmente à garantia de uma educação pensada a partir das especificidades dos povos do campo, além de a educação ser, acontecer e ser reinventada no território campesino (CALDART, 2012). É um currículo para uma escola do e no campo em construção, são políticas curriculares de Educação do Campo sem um fundamento último, e é esse "vazio normativo" (LOPES, 2015b) que acreditamos ser capaz de reinventar o curso e o percurso da Educação do Campo, a constituição de seu conceito, embora seja impossível pensar uma definição fixa do que seja Educação do Campo, visto a impossibilidade do fechamento do social.

Estas considerações seguem na direção da compreensão que, a Educação do Campo se confronta com a Educação Rural, mas não se constitui como uma "Educação Rural Alternativa", são na verdade hegemonias em disputas em constante (re)afirmação, disputam projetos, reivindicam novas demandas que denunciam, enunciam e anunciam novos sentidos nos currículos e nas políticas curriculares. Dito de outro modo, no campo da Educação do e no Campo, o direito, os saberes, os conhecimentos, são negociados diariamente nos espaços do entre-lugar das políticas curriculares/ dos currículos, ou seja, nos processos de recontextualização e tradução das políticas. Nesse contexto, os sentidos expressos nesta trajetória ampliam-se e deslocam-se nos movimentos nos processos de produção da política, pois consideramos que a escola bem como as políticas 
curriculares são "campos sujeitos a negociações, renegociações e disputas" como bem argumentam Ramos, Barreiros e Frangella (2012, p. 80).

Se o discurso 'por uma Educação do e no Campo' é estabelecido a partir da relação entre elementos (diferenças), esses elementos passam para o status de momentos (equivalências) durante a articulação e, dessa forma, os discursos se constituem por processos de identificações que se dão no campo do social. Nas palavras de Mendonça $(2015$, p. 76) “compreender o processo articulatório é decisivo para o entendimento da noção de que é pelo discurso - e não antes e nem tampouco fora dele - que as identificações sociais são constituídas”.

Nessa linha de compreensão, a Educação do Campo não se constitui enquanto um campo recente de contestação e de lutas na sociedade moderna ou nos dias atuais. E apesar de os discursos da Educação do campo guardar marcas de um antagonismo frente à Educação Rural, resulta da articulação pela luta que busca colocar nesse horizonte o direito dos camponeses à educação, "nasce de outro olhar sobre o campo" (ARROYO; CALDART; MOLINA, 2011, p.11). O termo Educação do Campo não marca um surgimento, aparição ou mesmo simples troca de nomenclatura, mas carrega em si uma construção histórica que a diferencia da Educação Rural oferecida por décadas pelo Estado e a constitui enquanto uma perspectiva antagônica. Essa articulação discursiva que constitui a hegemonia engendrada pelo Estado caminha frente ao controle e domínio do poder/ saber e alimenta um sistema desigual de reprodução que acentua as desigualdades sociais, a desvalorização cultural - de povos em detrimento a outros, de territórios em relação a outros, de saberes em relação a outros -, bem como submetendo povos à exploração, a partir de um modelo de educação elementar para o trabalho - a Educação Rural.

Levando essa reflexão mais longe, os movimentos sociais do campo, a partir de articulações políticas que tem como protagonistas os povos das florestas, das águas e do campo, entre outros (BRASIL, 2002), precisaram se articular diante de uma demanda única, um movimento 'Por uma Educação do Campo' que pudesse articular as diferentes demandas e hegemonizar-se, constituindose enquanto um movimento único. Mas, apesar de terem como objeto de luta uma demanda que representa os diferentes grupos, esses movimentos carregam outras lutas com sentidos e demandas peculiares. Em outras palavras, o movimento do campo precisou esvaziar-se dessas particularidades que carregam e os sustentam, para que assim, pudesse ser e constituir-se enquanto um movimento único Por uma Educação do e no Campo que representaria os movimentos sociais do campo, e resistiriam a modelos elementares e padronizados de educação e formação para os povos do campo. 


\section{EDUCAÇÃO DO E NO CAMPO: NO QUE TANGE O DIREITO À DIFERENÇA?}

As lutas em torno de uma Educação do e no Campo, não se dá na trajetória histórica de Educação do Campo de forma linear onde as conquistas são alcançadas e perpetuadas no âmbito da prática, seja no âmbito de políticas curriculares, seja nos currículos das escolas do campo. Tampouco, consideramos que exista um fundamento último nas políticas de Educação do Campo. Esses discursos se renovam e anunciam novas demandas em torno do que é significado enquanto Educação do Campo, qualidade, diferença. São essas demandas construídas nos processos de identificações sociais que possibilitam os jogos entre diferenças e equivalências nas articulações políticas. As políticas curriculares para a Educação do Campo são constituídas num campo de tensões, e os movimentos sociais do campo como protagonistas dessa luta, são inseridos nesse terreno de negociações e articulações políticas, que a partir de movimentos de "conformismos" momentos - e "resistências" - elementos - (LACLAU; MOUFFE, 2015), recriam-se e anunciam-se no campo do direito e educação, inscritos em processos democráticos e plurais.

A década de 1990 foi relevante, neste sentido, para a consolidação de outros movimentos iniciados pela universalização de uma educação básica e as diversas modalidades de educação Educação de Jovens e Adultos (EJA), Educação Especial, Educação do Campo - "que reconfiguram os espaços públicos e privados no quadro das lutas populares, ampliando o campo de conquista de direitos" (OLIVEIRA; CAMPOS, 2012, p. 237).

Tendo percorrido o caminho frente a "um passado" ainda presente nos dias atuais - a Educação Rural -, e na tentativa de delinear uma breve trajetória histórica de um campo "que não é recente" - a Educação do Campo -, propomo-nos a concentrar nossa atenção para um resgate histórico do decurso na constituição do nosso objeto de estudo - a Educação do Campo. Entendemos a relevância desses momentos históricos no campo da constituição de direitos por uma educação do campo instituída nas políticas curriculares e diretrizes curriculares. Neste nosso estudo, procuramos compreender as contradições entre o instituído nas políticas curriculares e os sentidos expressos no processo de recontextualização/tradução das políticas, compreendendo-o a partir do movimento cíclico dos diferentes contextos abordados por Ball $(2001 ; 2011)$.

A Educação do Campo foi proposta como um projeto antagônico ao modelo de educação engendrado pelo Estado, e em contraponto a esse silêncio frente à hegemonia estatal posta nas propostas da chamada Educação Rural ou Educação Rural no Brasil, contestava-se a demanda da diferença - nas políticas, nos currículos - o reconhecimento desses povos a partir de um novo olhar para as populações que no campo vivem, buscava-se repensar esse modelo e incluir esse novo projeto nas agendas políticas. 
Sobre as implicações e constituição do termo Educação do Campo é preciso fazer algumas observações. Não existe uma aproximação entre os termos campo e rural, esses termos não são semânticos. Os sentidos que inundam esses termos de significação não podem ser utilizados como sinônimos quando tratados na trajetória da Educação do Campo. Consideremos, pois, a partir dos estudos de Mendonça (2015) sobre os limites da democracia a partir de Laclau, que a Educação do Campo é um projeto de educação que nasce numa relação antagônica ao modelo de Educação Rural instituído, que, apesar de negar uma identidade - a identidade dos povos do campo - é a possibilidade de sua constituição. Dito de outra forma, é a partir da Educação Rural que a Educação do Campo é recriada como um projeto político de transformação da realidade instituída por décadas no campo, representado na relação antagônica frente ao poder estabelecido - a hegemonia dada pelo Estado.

Entende-se com o exposto que apesar de o trabalho ser relevante e parte constituinte para pensarmos a Educação do e no Campo, as demandas diferenciais ampliam os sentidos das lutas, entram na pauta das discussões os discursos sobre cultura, modos de viver em territórios diversos, saber/ conhecimento, entram em disputas e negociações no campo da Educação do Campo. Além disso, no contexto de traduzir os interesses postos nas agendas políticas (as demandas) para textos políticos, alguns sentidos particulares desaparecem e, ao universalizar-se provisoriamente, constituem novos vazios normativos, estes motivos de novas negociações. São essas faltas constitutivas, esses vazios normativos, que possibilitam o investimento e a criação de estratégias mais radicais e plurais no processo de traduzir as políticas (LOPES, 2015b). São a partir de docentes que se inquietam e estejam inscritos e se engajam em um projeto maior e democrático no âmbito das políticas, da educação, dos currículos para as escolas do campo, que a formação discursiva Educação do Campo escreve sua trajetória. Uma trajetória, que por mais que estejamos implicados na tentativa de fixar sentidos no que venha a ser a Educação do Campo, estamos submetidos aos deslocamentos, "imersos na luta entre a existência de uma totalidade inalcançável que julgamos a todo instante poder preencher" (LOPES, 2015b, p. 124), pensamos e defendemos ser essa falta que nos mobiliza a agir, a decidir e investir radicalmente em conteúdos normativos, políticas públicas e currículos mais justos e democráticos nas escolas do campo e, portanto, questionando políticas que intentam e fortalecem a centralização curricular.

\section{OS SENTIDOS NAS POLÍTICAS CURRICULARES PARA A EDUCAÇÃO DO CAMPO NOS PROCESSOS DE TRADUÇÃO: COMO SE FAZEM OS INVESTIMENTOS?}

A partir de um enfoque discursivo nos propomos a fazer a análise do corpus de entrevistas, através do qual acessamos o contexto da prática nas políticas compreendendo, o "entre lugar" 
constituído a partir dos processos de traduções nas políticas desenvolvidas pelos atores políticos/ os docentes nas escolas do campo. Buscando analisar os sentidos nas políticas de Educação do Campo nos discursos dos docentes de modo a compreender os contextos discursivos que norteiam as escolas do campo em Brejo da Madre de Deus - PE, construímos a análise em dois momentos, respectivamente, análise do corpus documental e do corpus de entrevistas, este último discutido neste texto.

Inicialmente, analisamos as noções de políticas e políticas curriculares nos discursos dos docentes. Neste ponto faz-se necessário, justificar o porquê tentar fazer-se compreender como os docentes pensam as políticas e como se veem atravessados nos processos e nos diferentes contextos. Muitas vezes, nos contextos das políticas opera-se de forma como se o universal tivesse um lugar absoluto a ser defendido (MATHEUS, 2009; LOPES, 2012). Os sentidos atribuídos às políticas de currículos nos discursos dos docentes nos remetem a essa compreensão, a noção de políticas enquanto conjunto de regras que podem contribuir para a educação de qualidade, caso sejam "seguidas" e "aplicadas".

Neste sentido, os discursos dos docentes PEC1 e PEC2 sobre as políticas curriculares, especificamente sobre as diretrizes para a Educação do Campo, caminham frente ao entendimento de que a partir dessas políticas, dessas regras, os sujeitos atores podem contemplar as mais diversas experiências da diversidade de povos do campo, indígenas, quilombolas e suas diferenças, tornando-se possível, ao seguir o caminho expresso nas diretrizes, chegar a supostos consensos $a$ priori - por exemplo, o discurso de "qualidade da educação" para as escolas do campo. Nas palavras de Lopes (2012, p. 712), “opera-se como se existisse um particular [demanda particular] que definitivamente pudesse (e devesse) se hegemonizar como universal [demanda universal]" [grifos nossos] e que ao mesmo tempo fosse representada, em sua totalidade no texto político.

Ainda de acordo com Lopes (2012, p. 713), a forma como as políticas, diretrizes, propostas curriculares e sistemas de avaliação tendem a ser compreendidos, caminham frente à constituição de um discurso que unifica "um centro de poder e encaminha a mudança curricular para uma dada direção, apagando as marcas da sua contingência, da constituição de seus projetos como particulares". Quando se pensa o caráter da contingência nas políticas curriculares ancorados na noção de democracia na perspectiva de Laclau e Mouffe (2015), nos cabe entender a importância de oportunizar dissensos, de modo que as diferenças e os conflitos se multipliquem, distanciando-se e desconstruindo a ideia de distribuição de saberes igualitários como constituidores e garantidores da qualidade (LOPES, 2012), na tentativa de pensar que, ainda assim, possa haver um conjunto de conhecimentos universais a priori, que garantam o reconhecimento da diferença, como se um 
conjunto de diferenças pudessem ser homogeneizados nos currículos, no caso específico, destas escolas do campo.

Nesse sentido, vale destacar que, os docentes quando questionados sobre as noções no que concerne aos textos das Políticas para a Educação do Campo, especificamente as diretrizes para a Educação do Campo, a Resolução CNE/CEB 01, de 03/04/2002, e a Resolução CEB/CNE 2, de 28/04/2008, em seus discursos expressam dois sentidos que se divergem em sua natureza. O docente PEC1 afirma conhecer os textos das diretrizes e as veem enquanto "texto legal com orientações para o trabalho na Educação do Campo" e ressalta que a partir da vivência e formação no curso de extensão do Programa Escola da Terra, foi possível aprofundar-se das diretrizes e utilizá-las no seu dia-a-dia em sala de aula. Em suas palavras, o docente afirma:

Elas [as diretrizes, as políticas curriculares] nos orientam, de forma melhor, a trabalhar com os nossos alunos no dia-a-dia, [...] são como um norte do que devemos trabalhar com os alunos e com a comunidade e que vão tirar as possíveis dúvidas que podemos vir a ter, podemos contar com um documento legal que orienta (PEC1, entrevista, Dezembro/ 2016 [grifos nossos]).

As políticas curriculares, no discurso empreendido pelo docente, são simplificadas à noção de que políticas são documentos escritos, orientações legais que direcionam a prática, ou seja, os sentidos expressos a partir do enunciado em destaque asseguram as políticas enquanto produções externas à escola, idealizadas nas instâncias governamentais e levadas à escola para serem seguidas e/ou aplicadas.

Esta análise construída a partir do sentido possível do discurso de PEC1 sobre a noção de políticas e o conhecimento das políticas sobre a Educação do Campo, também é recorrente no discurso de PEC2. Contudo, esta docente ressalta: "O que a gente vê e lê nas apostilas [nas diretrizes] a gente acaba aplicando os aprendizados que a gente teve" (PEC2, entrevista, Dezembro/ 2016 [grifos nossos]). Igualmente, compreende-se, a partir dos sentidos atribuídos pela docente às políticas enquanto "regras" ou "conjunto de orientações", as quais são possíveis de serem "aplicadas" no âmbito da prática.

Em face disso, Lopes (2004) ressalta que todas as políticas curriculares são políticas de constituição do conhecimento escolar, ou seja, conhecimentos construídos simultaneamente para a escola e pela escola. Desse modo, as políticas não se configuram como uma constituição de conhecimentos externos, apesar de também o ser, as políticas curriculares não se resume em regras e em textos políticos. 
As políticas curriculares não se resumem apenas aos documentos escritos, mas incluem os processos de planejamento, vivenciados e reconstruídos em múltiplos espaços e por múltiplos sujeitos no corpo social da educação. São produções para além das instâncias governamentais. Isso não significa, contudo, desconsiderar o poder privilegiado que a esfera de governo possui na produção de sentidos nas políticas, mas considerar que as práticas e propostas desenvolvidas nas escolas também são produtoras de sentidos nas políticas curriculares (LOPES, 2004, p. 111112).

Pensar na complexidade que envolve os processos da constituição das políticas, nos imprime a pensar as políticas de educação, para além de uma visão simplista que os considera genericamente enquanto textos de orientações organizados para a escola, em ações externas à escola. Vale destacar, com base nas conclusões de Ball et al. (2016, p. 173) sobre as políticas de educação no Reino Unido, que pensar em políticas curriculares é pensar em processos contingentes e que só podem ser potencialmente compreendidas e analisadas em seus contextos, pelo discurso, pois, "as políticas são formações discursivas; elas são conjuntos de textos, eventos e práticas que falam com processos sociais mais amplos de escolaridade".

Tal perspectiva empreendida por Ball (1992) e Ball et al. (2016), sobre a importância de compreender as políticas em seus contextos (investimento ao qual intentamos com o texto ora empreendido) nos permite conceber as políticas como "momentos" complexos, e em uma perspectiva discursiva, nas palavras de Lopes (2004):

As políticas curriculares são processos de negociação complexos, nos quais "momentos" como a produção dos dispositivos legais, a produção dos documentos curriculares e o trabalho dos professores devem ser entendidos como associados. Os textos produzidos nesses "momentos", sejam eles registrados na forma escrita ou não, não são fechados nem têm sentidos fixos e claros (LOPES, 2004, p. 112).

No que concerne à linha de reflexão que segue a docente temos uma preocupação. A nossa preocupação refere-se às noções atribuídas nos diferentes contextos das políticas, pois muitas vezes, se operam como se o universal tivesse um lugar absoluto, fixo e fechado a ser defendido (LOPES, 2012). Convém ainda registrar que há uma relação em comum entre os sentidos estabelecidos no discurso dos docentes PEC1 e PEC2 com os sentidos possíveis sobre as diretrizes expressas pela docente PEC3. A compreensão que estas diretrizes constituem-se enquanto um texto político que direciona e organiza o ensino nas escolas do campo parece-nos ser um consenso. Neste sentido, a docente afirma conhecer as diretrizes e ter trabalhado com essas políticas no projeto de intervenção de cunho social, pedagógico e político exigido pelo curso, citando algumas demandas que ganharam 
força nas agendas políticas de discussão sendo hegemonizadas e constituídas enquanto texto político:

Eu trabalhei com ela [as Diretrizes] no projeto que a gente fez da Escola da Terra e conheço o texto, conheço o que ele diz a respeito de como se trabalhar, do que fazer, da organização, da formação dos professores, da questão do financiamento, da questão da identidade das escolas (PEC3, entrevista, Janeiro/ 2017[grifos nossos]).

Tomando por base o discurso da docente, compreende-se que a mesma possui conhecimento sobre as diretrizes que fundamentam e que integram as políticas de Educação do Campo e, mesmo mostrando-se não conhecer o $\mathrm{PME} / \mathrm{BMD}^{2}$, nos movimentos possíveis no contexto da prática mantem-se frente ao projeto de Educação do Campo que pretende hegemonizar, dialogando com as demandas dos sujeitos que integram a comunidade local da escola em que leciona, bem como a partir dos textos políticos, especificamente as diretrizes.

O discurso da identidade docente presente no discurso da docente PEC3 aponta a preparação para o ensino no campo, uma preparação a partir de cursos de formação continuada, especificamente o Programa Escola da Terra e o posicionamento do sujeito frente à perspectiva de Educação do Campo que o mobiliza.

[...] Faz sete anos que eu trabalho na educação do campo e faz basicamente dois anos que eu venho tendo acesso aos documentos, a essas Diretrizes, e só a partir desse momento [...] em especial depois do Programa Escola da Terra é que eu tenho a visão de que campo e cidade são diferentes em relação à cultura, mas que precisam ser equiparados em relação à educação (PEC3, entrevista, Janeiro/ 2017).

E mais,

Eu não trabalhava com os meninos, tratando eles, a educação ou até mesmo o meu planejamento como uma escola do espaço rural. Eu trabalhava como se estivesse trabalhando na cidade, o planejamento era como se estivesse trabalhando na cidade (PEC3, entrevista, Janeiro/ 2017).

Para além, do discurso legal, a docente enfatiza em seu discurso, sentidos da identidade do docente, o não silenciar sobre essa constituição da identidade do docente enquanto um processo constante e impossível de chegar a sua plenitude (LOPES; BORGES, 2015), mas possível de investir radicalmente em ações, teórico e políticas mais justas e plurais (LOPES, 2015a). Esse discurso nos coloca a refletir sobre a posição do sujeito no contexto da prática e do seu

\footnotetext{
${ }^{2}$ Plano Municipal de Educação de Brejo da Madre de Deus, cidade do agreste de Pernambuco.
} 
envolvimento frente aos processos de identificações no traduzir das políticas, os sentidos de ser um professor do campo envolvido na luta pelo acesso ao direito à Educação do e no Campo, esses investimentos movimentam-se frente "as demandas por reconhecimento das especificidades históricas que constituem esses sujeitos de direitos” (MOLINA, 2012, p. 593).

A ideia de constituir-se enquanto docente do campo nos remete ao discurso da identidade docente e a ideia de preparação para a atuação nas escolas do campo frente a processos de formação e, para isso, exigem-se posicionamentos políticos dos sujeitos-atores envolvidos nestes processos. Sendo assim, faz-se necessário que o docente seja responsável por entender o contexto em que está inserido, dessa forma, os sentidos no discurso da docente nos coloca frente às evidências de que mesmo havendo "imperativos de políticas, sempre haverá alguns espaços alternativos para pensar de forma diferente" (BALL et al., 2016, p. 208), alguns pensamentos podem mobilizar investimentos frente ao discurso de justiça social, outros podem vir a contribuir para uma política mais democrática e plural, e apesar dessas possibilidades e invenções não ser previsíveis, nem planejadas, são inscritas no projeto hegemônico que os sujeitos-atores defendem e negociam no contexto da prática.

Paralelamente a esta compreensão, aprofundamos a análise dos modos que os docentes concebem as políticas, bem como os sentidos que atribuem a estes textos. Neste aspecto, dois sentidos são consensos ao mesmo tempo em que um discurso se afasta. Iniciemos, pois, com o discurso que se afasta e considera que as políticas são ações externas às escolas do campo e que pouco dialoga com a realidade, com o contexto da prática. Nesta linha de reflexão, quando indagados sobre a noção de políticas de Educação do Campo e se nas diretrizes tem algum ponto que acreditam distanciar-se da realidade local, a docente PEC2 em seu discurso, aponta que,

As leis [o docente refere-se às políticas de Educação do Campo] têm suas falhas né? ... e quando fazem pesquisa para aplicar alguma coisa eles não aplicam no geral, eles buscam escolas que vivem um sonho diferente, uma realidade totalmente diferente da nossa (PEC2, entrevista, Dezembro/ 2016).

O discurso da docente PEC2 nos imprime a pensar a visão dos processos políticos como contextos separados, com dinâmicas distintas e que podem ser pensados separadamente, como se os processos das políticas não fossem cíclicos e imbricados. Pensar nas políticas como produções exclusivas do poder central nos imprime desconsiderar as articulações políticas que são engendradas pelos movimentos sociais do campo frente aos projetos hegemônicos de educação que se pretendia para o campo, é o caso da Educação Rural e Educação do Campo, que são perspectivas 
que se antagonizam. Sobre essa "armadilha no debate" construído historicamente no campo das políticas e da compreensão de como são operadas, é que Lopes (2004) nos fala:

Os dirigentes questionam as escolas por não seguirem devidamente as políticas oficiais, e os educadores criticam o governo por produzir políticas que as escolas não conseguem implantar. Em ambos os casos, parece-me, tem-se o entendimento da prática como o espaço de implantação das propostas oficiais, sendo as políticas curriculares interpretadas como produções do poder central - no caso, o governo federal (LOPES, 2004, p. 111).

Os textos políticos, enquanto "tentativas de representação da política, sempre busca fechar a política em uma dada significação, fixar determinadas identidades e produzir determinados consensos" (p. 710-711). Em outras palavras, significa dizer que quando pensamos a contingência nos textos políticos, parece-nos que estes textos não são capazes de compreender ou fixar sentidos de uma vez por todas, e que a priori garanta a qualidade da Educação do e no Campo que se pretende. Pensar as normatividades enquanto campo que exige decisões entre diferentes possibilidades é pensar e assumir as políticas enquanto "atos de poder que tentam fixar sentidos nas relações sociais" (p. 120).

Contudo, a partir das análises empreendidas no corpus das entrevistas, podemos apostar que os sujeitos-atores, os docentes, imersos na linguagem e nas traduções constantes, que os contextos discursivos que norteiam as escolas do campo do município do Brejo da Madre de Deus - PE tencionam sentidos na tentativa, precária e contingente, mas ainda assim necessária de atingir, ou melhor, constituir, uma Educação do e no Campo de qualidade, como podemos ver nos consensos dos discursos da professora PEC3 e em menor intensidade no discurso do docente PEC1. Pensar nas possibilidades de invenções teóricas e políticas comprometidas com a democracia radical (LACLAU; MOUFFE, 2015) no campo discursivo da Educação do Campo, nos possibilita entender que os currículos para estas escolas movimentam-se e se hibridizam na constituição e na significação do que venha a ser Educação do Campo, tendo em vista que não se pode pensar essa formação discursiva fora do terreno da contingência.

Portanto, o que se busca e que ao mesmo tempo caracteriza o processo democrático nas políticas de currículos para a Educação do Campo é que, pensadas a partir da noção de normatividades vazia (LOPES, 2015b), considerando a impossibilidade de fixação de uma política, um currículo que venha a constituir um conjunto de conteúdos que fixem essas diferenças, e embora exista a tentativa contingente de atingir uma plenitude, contingente e precária, estes mesmos são vazios normativos constituídos pela contingência nas políticas curriculares e possibilitam que 
investimentos radicais possam ser instituídos no âmbito dos contextos das políticas e nos "entre lugares" nos processos de traduções. São esses investimentos não previsíveis - pois, na verdade, não se sabe aonde chegar - possibilidades de reinventar as políticas, as possíveis disputas e negociações na tentativa de alcançar uma plenitude ausente, que mobiliza os docentes no contexto da prática a agirem, a decidirem, a representar o que não pode ser representado e a significar o que sempre estará em processo de significação e flutuação de sentidos. É a ampliação dos espaços de poder a partir dos investimentos teóricos e políticos por parte dos docentes, que podem favorecer a constante luta política e a tradução de propostas curriculares mais democráticas e plurais para as escolas do campo do município.

\section{CONSIDERAÇÕES FINAIS - UMA TENTATIVA (PROVISÓRIA) DE FINALIZAR}

Na luta por significação das políticas, dos possíveis currículos para os povos do campo como forma de legitimar as articulações políticas em torno de demandas que reconheçam as especificidades dos povos do campo, os sujeitos-atores, os docentes, no contexto da prática se articulam de forma a legitimar em sua prática discursiva as Políticas de Educação do Campo ou se colocar em oposição a ela, vinculados ao projeto de Educação do e no Campo que se pretende defender/ negociar. A defesa de uma proposta, bem como a oposição a ela, depende de demandas existentes no contexto da prática, bem como das negociações e recontextualizações que os docentes fazem nos processos de tradução das políticas, no "entre lugar" entre os contextos das políticas. Tais demandas e negociações são legitimadas por discursos, a partir do envolvimento político e dos posicionamentos dos sujeitos-atores frente ao projeto de Educação do e no Campo ou em oposição a este projeto, fomentam articulações para tentar homogeneizar a proposta que defende.

O discurso pedagógico no contexto discursivo das escolas do campo do Brejo da Madre de Deus- PE assumiu contornos híbridos, embora o discurso de traduzir as políticas de Educação do Campo seja pautado nas demandas que nas articulações entre equivalências e diferenças, precariamente e contingencialmente, tornaram-se universais durante a constituição histórica da Educação do Campo no Brasil. As análises empreendidas, apontam que as políticas de Educação do Campo quando consideradas enquanto formação discursiva, por si só não oferece garantias de uma Educação do e no Campo, mas o fato de existir as Políticas de Educação do Campo, bem como a partir das demandas que as constituem, possibilita que práticas mais plurais e democráticas com os saberes-fazeres dos diferentes povos do campo aconteçam e tornem-se efetivas nessas escolas do campo. São nos espaços das traduções dessas políticas que os sujeitos-atores, os docentes, constituem investimentos mais democráticos e plurais. 
Os discursos dos docentes ainda apontam que os sentidos que os docentes atribuem à Educação do Campo e ou Educação Rural, logo, está correlacionada com o posicionamento do sujeito nestas escolas do campo diante do que se entende enquanto Educação do Campo e de como se identifica no lugar, enquanto docente do campo. Esses discursos estão em jogo nas permanentes tensões no contexto discursivo das escolas do campo na rede municipal de ensino pesquisada. Enquanto alguns docentes posicionam-se em contrapartida às desigualdades sociais a que o campo historicamente sofrera, promovendo a partir de invenções no contexto da prática o reconhecimento do lugar, das diferenças, a visão de Educação Rural enquanto projeto de educação antagônica à Educação do Campo, bem como a importância de considerar as especificidades dos diferentes povos nos currículos, seja na tentativa de hegemonizar uma Educação do e no Campo, seja na organização da escola com base no desenvolvimento do campo.

Parece-nos que um dos nossos maiores achados constitui-se nos investimentos possíveis que os docentes fazem nos "entre lugares" dos processos de tradução, nos contextos das políticas. Pensar em caminhos para ampliar as possibilidades democráticas no campo da educação, especificamente, na educação para os povos do campo no contexto analisado, nos imprime a pensar que existem alguns caminhos.

O primeiro se inscreve no entendimento que não é possível construir um currículo único no âmbito do município e das escolas do campo quando se pensa e pretendem-se políticas e currículos pensados a partir da noção de democracia. Não se presume a elaboração de propostas e políticas curriculares municipais ou a níveis nacionais que pressuponha encerrar com as possibilidades da constituição de outros currículos nestas escolas do campo, seriam essas, também, invenções políticas. Esses investimentos políticos se inscrevem na ampliação de espaços de poder no âmbito do município, das escolas, possibilitando que outras negociações, tensões e articulações políticas por demandas venham a surgir e tornar-se equivalentes.

Por fim, cabe ressaltar a relevância de pensar os processos de decisão dos docentes nos processos que envolvem as relações de identificações no espaço-tempo do currículo, das traduções das políticas, nestas escolas do campo, implicando na escolha de possibilidades e intervenções teóricas e políticas, a partir de discursos mais plurais. Neste sentido, a responsabilidade com a formação docente e o compromisso teórico e político na atuação nestas escolas, são alguns dos significantes que vem sendo mobilizados pelos docentes na tentativa de expressar e investir teoricamente e radicalmente no campo da Educação do Campo, especificamente, nos contextos discursivos das escolas do campo. 


\section{REFERÊNCIAS}

ARroYO, M.G.; CALDART, R.S.; MOLINA, M.C. (Orgs.). Por uma Educação do Campo. 5. ed. Petrópolis, RJ: Vozes, 2011.

BALL, S.; MAINARDES, J. (Orgs.). Políticas educacionais: questões e dilemas. São Paulo: Cortez, 2011.

The policy processes and the processes of policy. In: BOWE, Richard; BALL, Stephen; GOLD, A. (Orgs.). Reforming education \& changing school: case studies in policy sociology. Londres - New York: Routlegde, 1992.

; MAGUIRE, M. ; BRAUN, A. Como as escolas fazem as políticas: atuação em escolas secundárias. Ponta Grossa: Editora UEPG, 2016. Tradução Janete Bridon.

BHABHA, H. O local da cultura. Trad.: Myriam Ávila, Eliana Lourenço de Lima Reis, Gláucia Renate Gonçalves. Belo Horizonte: Editora MG. 1998.

BOWE, R.; BALL, S.; GOLD, A. Reforming education \& changing school: case studies in policy sociology. Londres - New York: Routlegde, 1992.

BRASIL. Ministério d Educação, Conselho Nacional de Educação/ Câmara de educação Básica. Resolução Nº 01, de 03 de abril de 2002: Diretrizes Operacionais para Educação Básica nas escolas do campo. Diário Oficial [da República Federativa do Brasil], Brasília, DF, 09 de abril de 2002.

. Ministério d Educação, Conselho Nacional de Educação/ Câmara de educação Básica. Resolução Nº 02 , de 28 de abril de 2008: Estabelece diretrizes complementares, 212 normas e princípios para o desenvolvimento de políticas públicas de atendimento da Educação Básica do Campo. Diário Oficial [da República Federativa do Brasil, Brasília, DF, 29 de abril de 2008.

CALDART,R. S. Educação do Campo. In: CALDART et. al. Dicionário de Educação do Campo. 2. ed. Rio de Janeiro, São Paulo: Escola Politécnica de Saúde Joaquim Venâncio, Expressão Popular, 2012.

FRANGELLA, R. C. P. ; BARREIROS, D. R. A. Buscando o sentido de política nos estudos curriculares - perspectivas de análise em questão. In: ANPED. Anais da 31. Reunião... Caxambu, MG: ANPED, 2008.

LACLAU, E. ; MOUFFE, C. Hegemonia e estratégia socialista: por uma política democrática radical. Trad.: Joanildo A. Burity; Josias de Paula Jr; Aécio Amaral.São Paulo: Inttermeios, Brasília: CNPq, 2015.

LOPES, A. C. (2015a). Por um currículo sem fundamentos. Linhas Críticas. Brasília, DF, 21 (45), 445-466, Disponível em: <http://periodicos.unb.br/index.php/linhascriticas/article/view/16735> Acesso em: 23 ago. 2017.

; BORGES, V. Formação Docente, um projeto impossível. In: Cadernos de Pesquisa [on-line], v. 45, n. 157, p. 486-507, jul./set., 2015. Disponível em: <http://www.scielo.br/pdf/cp/v45n157/1980-5314-cp-45-157-00486.pdf > Acesso em: 13 jun. 2017.

. Normatividade e intervenção política: em defesa de um investimento radical. In: LOPES, A. C.; MENDONÇA, D. (Orgs.). A teoria do discurso de Ernesto Laclau: ensaios críticos e entrevistas. São Paulo: Annabrume, 2015 b.

. Democracia nas políticas de currículo. In: Cadernos de pesquisa. [on-line], v. 42, n. 147, p. 700-715 set./dez. 2012. Texto-base da conferênciaministrada no Instituto de Investigaciones sobre la Universidad y la Educación IISUE, da Universidad Nacional AutÓnoma de México- UNAM.

Discursos nas políticas de currículo. Currículo sem Fronteiras, v. 6, n .2, p. 33-52, jul./ dez. 2006.

Política, conhecimento e a defesa de um vazio normativo. In: MENDONÇA, D. ; RODRIGUES,L. P.; LINHARES, B. (Orgs.). Ernesto Laclau e seu legado transdisciplinar. São Paulo: Intermeios, 2017.

. Políticas curriculares: continuidade ou mudança de rumos?. In: Revista Brasileira de Educação, n. 26, p. 109118, maio/ago. 2004.

. Tensões entre recontextualização e hibridismo nas políticas de currículo. In: ANPED. Associação Nacional de Pós-Graduação e Pesquisa em Educação. Anais 28 ${ }^{\text {a }}$ Reunião... Caxambú: MG, 2005. Disponível em: <http://28reuniao. anped.org.br/ >. Acesso em: 13 jun. 2017.

; CUNHA, E. V. R.; COSTA, H. H. C. Da recontextualização à tradução: investigando políticas de currículo. In: Revista Currículo Sem Fronteiras, v. 13, n. 3, p. 392-410, set./ dez. 2013.

; MACEDO, E. Teorias de Currículo. São Paulo: Cortez/Faperj, 2011.

. O foco na organização curricular. In: LOPES, Alice C. Políticas de integração curricular. Rio de Janeiro: EdUERJ. 2008. (cap. 3, p. 33-39). 
. Teoria pós-críticas, política e currículo. Revista Educação, sociedade e culturas, n. 39, p. 7- 23, 2013.

MENDONÇA, D. O limite da normatividade na teoria política de Ernesto Laclau. Lua Nova (Impresso e On-line), v. 91, p. 135-168, 2014. Disponível em: <http://www.scielo.br/pdf/ln/n91/n91a06.pdf>. Acesso em: 13 jan. 2016.

Pensando (com Laclau) os limites da democracia. In: LOPES, A. C.; MENDONÇA, D. A teoria do discurso de Ernesto Laclau: ensaios críticos e entrevistas. São Paulo: Annablume, 2015.

MOLINA, M. C.; SÁ,L. M. Escola do Campo. . In: CALDART et al. Dicionário de Educação do Campo. 2. ed. Rio de Janeiro, São Paulo: Escola Politécnica de Saúde Joaquim Venâncio, Expressão Popular, 2012.

MOUfFE, C. Por um modelo agonístico de democracia. Revista Sociologia Política, Curitiba, 25, p. 11-23, nov. 2005.

OLIVEIRA, L.M.; CAMPOS, M. Educação Básica do Campo. In: CALDART et al. Dicionário de Educação do Campo. 2. ed. Rio de Janeiro, São Paulo: Escola Politécnica de Saúde Joaquim Venâncio, Expressão Popular, 2012.

RAMOS, A. H. ; BARREIROS, D. ; FRANGELlA, R. C. Políticas de currículo e escola: entre fluxos e negociações. In: FERRAÇO, Carlos E; GABRIEL, Carmen T.; AMORIM, A.C. (Orgs.). Políticas de Currículo e escola, Campinas, São Paulo: FE/Unicamp, 2012. E-book, GT Currículo. 2012. Disponível em: <www.bibliotecadigital.unicamp.br>. Acesso em: 10 maio 2017.

RAMOS, J. R. S. Políticas Públicas e Educação do Campo: uma análise dos contextos discursivos que norteiam as escolas do campo no município do Brejo da Madre de Deus-PE. 2017. 237f. Dissertação. (Mestrado em Educação Contemporânea) - PPGEDUC, Universidade Federal de Pernambuco - UFPE, Centro Acadêmico do Agreste - CAA, Caruaru, 2017. 


\section{RESUMO}

Este artigo discute sobre os contextos discursivos que norteiam as políticas de currículo para a Educação do Campo no município de Brejo da Madre de Deus - PE. Com base em Laclau e Mouffe (2015), analisamos os sentidos das políticas, dos currículos, da Educação do Campo, nos discursos dos docentes, buscando compreender quais são as invenções e/ ou investimentos que os docentes fazem a partir dos processos de traduções das políticas. Para tanto, realizou-se entrevistas com docentes de três escolas, de modo a entender os sentidos nas negociações e nos processos de tradução das políticas no contexto da prática. Os resultados revelam que os sentidos da Educação do Campo são instituídos a partir das demandas e dos investimentos radicais que os docentes fazem nas disputas por hegemonias nos currículos das escolas do campo.

Palavras-chave: Políticas de Currículo. Educação do Campo. Discurso.

\section{CURRICULUM POLICIES FOR RURAL EDUCATION: HOW ARE INVESTMENTS MADE?}

\section{ABSTRACT}

This article discusses the discursive contexts that guide curriculum policies for Rural Education in the municipality of Brejo da Madre de Deus - PE. Based on Laclau and Mouffe (2015), we analyze the directions of policies, curricula, Rural Education, in teacher's discourses, seeking to understand what are the inventions and / or investments that the teachers make from the processes of translations of the policies. For this purpose, interviews were conducted with teachers from three schools, in order to understand the directions in the negotiations and in the processes of translation of policies in the context of practice. The results show that the directions of the Rural Education are established based on the demands and the radical investments that the teachers make in the disputes for hegemonies in the curricula of the rural schools.

Keywords: Curriculum Policies. Rural Education. Discourse.

\section{POLÍTICAS DE CURRÍCULO PARA LA EDUCACIÓN DEL CAMPO: DE QUÉ FORMA SE HACEN LAS INVERSIONES?}

\section{RESUMEN}

Este artículo discute sobre los contextos discursivos que orientan las políticas de currículo para la Educación del Campo en el municipio de Brejo da Madre de Deus - PE. Con base en Laclau y Mouffe (2015), analizamos los sentidos de las políticas, de los currículos, de la Educación del Campo, en los discursos de los docentes, buscando comprender cuáles son las invenciones y / o inversiones que los docentes hacen a partir de los procesos de traducciones políticas. Para ello, se realizaron entrevistas con docentes de tres escuelas, para entender los sentidos en las negociaciones y en los procesos de traducción de las políticas en el contexto de la práctica. Los resultados revelan que los sentidos de la Educación del Campo son instituidos a partir de las demandas y de las inversiones radicales que los docentes hacen en las disputas por hegemonías en los currículos de las escuelas del campo.

Palabras clave: Políticas de Currículo. Educación del Campo. Discurso. 